\title{
The Nature and Concept of Meta-artistic Objects
}

\author{
Benjamín Valdivia \\ Professor, Art, Architecture and Design, University of Guanjuato \\ E-mail: valdivia@ugto.mx
}

\begin{abstract}
This paper introduces two concepts useful for the understanding of current trends in art. One of them is the concept of meta-art, which is proposed here because of the perception that contemporary art goes beyond the traditional borders of art, transforming the aesthetic question (is it beauty?) to a more ontological question (what is it?). Diverse elements are identified at the borders of artistic expression, as the question starts to implicate the changes caused by the notion of the meta-artistic. The second concept deals with the other main category of judgement of art, which was formerly defined by beauty, and yet now gets displaced in the limits of the meta-artistic by another process that we call aesthetic impact. This given pair of theoretical instruments help in a better understanding the astonishing objects developed by the artists of our time.
\end{abstract}

Keywords: aesthetic impact, beauty, contemporary art, fragmentation, Meta-artistic, end of art.

\section{Introduction}

The concept of 'meta-artistic'i eschews any form of historical posterity and continuance of art works. An object is meta-artistic not because it extends the inner field of an art, but because it goes beyond or falls outside of art. Simply put, it is no longer art as we knew it. In these objects, the problem of aesthetic meaning has shifted towards another more ontological characterii. The crucial point for this rupture is the image. It deals with a presentation of the image of what was art, with all that art implies, as it is just a presentation, not a representation. Let us consider this aspect of the meta-arts first.

\section{The Nature of the Meta-Artistic}

Since they are already part of the recent condition of social life meta-artistic objects require to be placed within theoretical delineations. We shall refer to elements that help in characterization of the meta-artistic phenomenon with the understanding that subsequent reflection on each of these items here listed will be necessary. Our strategy for deeper analysis will oppose these meta- 
artistic components to the most accepted beliefs about what is generally considered as truly and directly artistic, and to capture in this negative way, the critical meaning and thinking that it implies.

In the first place, we might think of meta-artisticity. Objects are meta-artistic when they move in a surrogate and ontological realm of art: it is not art but it acts as if everything it did were. These objects are not directly considered as art because they do not meet stipulations that are usually set up for traditional artistic expectations. The meta-artistic object does not seek beauty, it does not conform to spiritual unity, in which the concept of art is unified with its expression, and neither does it intend to become an essentialized manifestation. In general, although it follows artistic standards, parameters, and procedures, the meta-artistic object does so in a stopgap, fragmentary, and tendentious way with respect to its constitutive conceptuality or its mere physical presence.

As mentioned above, the primary value of a meta-artistic object is not beauty, but rather, as we will see later in this text, an aesthetic impact that is realized as shock towards the sensibility, more than any other technical, expressive, or configurational effectiii. Analogous to axiological discoveries at the end of the nineteenth century, art was also recognized to create effects on quantitative scale. The impact created by an object could be considered a feasible indicator of its recognition in society just as every object had its place in a scale of values. Art thus widens the limits of sensibility by proposing new and aesthetic objects never before imagined. 'Beauty', even if captured in an unimaginable and unexpected shape, is now no longer the main reference that of a relationship between people and the would-be-perceived object. In conventional art there is also a demand of novelty over sensibility, whose aim is to model a perception of artistic objects based on the expectation of newness. One of the outstanding ways in which art ceases to be that kind of thing and eventually begins to acquire the definition of a meta-artistic process is by virtue of having a temporary existence: meta-artistic objects do not value longevity of art as was sought by artists in previous epochs. The greater the number of ephemeral components involved in the process, the greater is the renunciation of permanence. The use of materials that could be easily destroyed or dismantled is opposed to idea of the subsistence of their work of art which was visible in the "eagerness of centuries" of artists who aspired to immortalize their work of art. Whether they succeeded or not is another story, but the declared intention reveals the transcendental sense with which the artistic product was conceptualized. This issue, of course, is interwoven with beauty since the material or medium chosen were determined by an underlying feeling of assumed dignity. Marble was preferred over sand because of its durable qualities and as such marble determined the nobility of the artist's creativity: a construct in sand would be proverbially disposable. By that logic an extreme comparison would suggest that a meta-artistic work will prefer sand over marble, newspaper over canvas, fashion over tradition. In other words meta-art is more seriously concerned with the exaltation of the instantaneous.

To achieve aesthetic impact, the mere presence of the product will suffice at this opportunity. Moreover, within years or weeks, new ephemerality will come to substitute today's product before our very senses. With the aim of destroying tradition, Memory - or the memorable thing is no longer appreciated in meta-artistic objects and the spotlight remains on what is sensorially perceivable for the moment. For this purpose, it is sufficient that an object is perceived rather than remembered. Much of what is achieved in the transition from the artistic to the meta-artistic is 
closely linked to the conception of artists as producers. In arts, aesthetic meanings are considered responsibility of artists. The public confronts the work to discover those meanings. Shakespeare created the verbal material of Lear or Titania in such a way that it is original, eternal, and meaningful for the public to discover all that. In contrast, and according to some theories of reception, the meta-artistic object does not contain a meaning ultimately defined by the artist but expects that an open public participation will complete the meaning of the object. Once it is known that the artist is not responsible for the meaning, but is only positioned at the starting place of the work of art, the status of artistic development could be abandoned. Another aspect of meta-art is the choice of the prefabricated, recycled, or industrial medium of expression. Thus, a piece of cloth or newspaper can replace the area on the canvas that is traditionally always painted by the artist who respects the uniformity and continuity of application for a medium. But the artist of meta art may decide not to paint ia patch and instead place a bandage. The question is how much of the painting can be replaced by fabric. The meta-artistic response is: the whole painting. The historic emergence of the collage is a proof of this process. The same happens in other expressive forms: the noise of machines replaces musical development; a (non-operating) urinal is a sculpture; the poem takes fragments from newspaper to complete a verse. Earlier, artists created their form from a given set of material; now the meta-artistic creator selects fragments from previously existing social products and accommodates them in accordance to the new fate that the artist invokes for it. Choice or chance replaces the method of preparation and elaboration. For example, an artist prefers to use three-dimensional pieces made with selected elements found in a landfill instead of using traditional sculptural craft.

The fact that artists use prefabricated material instead of customary media is a fact that leads us to another facet of meta-art: the scope of meanings posited by the artist are incomplete, given that it is dependent on completion by the public. Heidegger's discussion of the definition of the content of a work of art began with the obvious fact that the artist is someone who makes art (and, in turn, the artwork is that object produced by the artist). Now, this is no longer evident: the receiver (spectator) does not necessarily recognize this product as a work of art but as an object that incites in the onlooker an ontological question: what is this? Derivatively, and at the bottom of the discussion of Heidegger, what do we call the author of that object, who does everything to make it look counterfactually like a work of art but does not allow us to define the product as a work of art? Hence, we have prefabricated material, dependent meaning and absence of the structural principles of beauty. Our opinion is that meta-artistic authors do not create art works, but proposals. It seems that we are not meant to recognize the worth of art, as was expected before. Neither is the exaltation of sensitivity set forward on capturing the ideal unity of an objectified spiritual conception. Many of these aspects now fall on-in terms of sensitive capabilities - the receivers of the art. By exhibiting a urinal outside of its sanitary context, without the pipe and the water supply and drainage, without the technical arrangement and, most importantly, without the artist making choices in design, materials or meaning, it brings us to the question related to what Duchamp is doing? We consider that Duchamp to have made a proposal: he has shown us that these things can be seen in this way. The author of the proposal guides our senses towards already given social items.

As mentioned previously, we should further develop and meditate on each of those aspects in terms of the meaning as it expresses in time. Here, we emphasize on a general outline. With this 
understanding, we will leave behind, for the moment, the phenomenon of the proposal, and shall see that artist, who sometimes do not even touch the very materials that construct their objects have replaced the technical artistic procedure with the act of assemblage. Their work is offered through objects chosen from what is already available to the society of the time, and their contribution is merely an assemblage. The compilation of a 'work' - as in information technology procedures - is achieved somewhat like in programming units or modules that compile a 'work' together. The meta artist is not one that has made the parts but one who assembles them. This artist makes a proposal, in which our sensitivity is confronted with a compilation of fragments put together in a pile of elements that had never previously been gathered for aesthetic meaning. Therefore, today the meta-artistic author or painter may have a statute of plastic artist without dominating over skills of drawing, in the same way as a composer who does not know the notes. The most important thing here is the ability to gather material, even without the requirement or presence of correct previous technical criteria. In this way, meta-artistic objects are closely related to popular and folk art, taking components from pre-existing social modules, which they then substitute $e^{\text {iv }}$.

We must recognize that to understand the character of the assemblage in meta-artistic objects, interventions of chance and externality are crucial. So, the artist's compilation is not something where absence of any part makes the whole representation suffer, since all its parts can be discarded or supplemented by other even dissimilar components. As we are dealing with objects that are chosen, they do not imply that the artist had a deep expressive commitment with these materials in forming the work. We note that the spiritual unity which in other time was necessary for art is not present in meta-artistic objects: its foundation is the conceivable. Not only in terms of its fragmented status, but the composition also corresponds to a meaning that is yet to be completed by the receiver. So, the proposal can move in any direction. In addition to this, we may consider that any part of the meta-artistic process can be adapted to other courses or other elements and still maintain the sense of the proposal. Since the entire assemblage is supplantable, the artist does not seek, then, traditional modes or procedures, but the reach of an aesthetic impact of the proposal. The intrinsic originality of this impact faces an objective uncompromising originality. We end this short tour on characterizing the meta-artistic pointing to a deeper issue: the "state of thing", that Heidegger argues is the basis of existence of the work, has been put in doubt. Meta-artistic objects insist more on their concept than its real objectification. We are, perhaps, facing a transformation of the ontological basis of objects to-be-perceived; now the image is heavier and its condition ephemeral. We consider that contemporary sensibility confers priority to concept or image over the state of thing, what may be referred to as a state of presence. It is the present time, exalted over the transcendent matter. The sensation of the proposal is accepted as valid even on weak material configuration of works. The public discovers, builds, or completes what the artist means. Then, the character of this contemporary form of expression, in its theoretical analysis, must include the fact that their objects are not artistic but meta-artistic. These objects are not supposed to be beautiful but do have an aesthetic impact. The meta-artistic renounces permanence and becomes instantaneous; it is not produced but proceeds largely by the choice of the prefabricated materials or a copy of them; they are not works but proposals, they do not follow a technical tradition but are assembled, they are not based on the need of unity, but on the contingency of the fragmentary; they are not commited to their configuration 
and since any of the elements is replaceable; they tend to replace the state of thing with the state of presence. Facing all these aspects, this kind of objects is where contemporary sensibility is formed. For all of the above we will have to deal with in future occasions.

\section{Aesthetic impact as meta-artistic category}

A major consequence of modernity has been the habit of criticism. This healthy cultural condition allowed the intense development of science since the seventeenth century up to such superb technological applications that are almost capable of artificially reproducing the human being, or at least the human body. Therefore, the artistic dimension has always engaged in creating what is different from the given: the new imaginary, the unprecedented, and a previously non-existent invention. To accomplish its labor as a reformer, artists have constantly renunciated the predecessors' material, medium or procedure. Of course, achievements of individual artists have been variously repeated by other artists or recovered in some way by subsequent generations; but, along with this survival, new forms are always generated. The proverbial waiving of the given banner, so characteristic of art, naturally adapts to the critical demands of modernity. So, modern art is situated in its very field when asked to be a vehicle of technical and ideological changes. Art simply needs to remain the same to be another.

Without belittling its adaptability, the art world was gradually losing its traditional foundations during modernity due to two occurrences: the blurring of its distinctive borders and, along with it, the dispersion of its characteristics among non-artistic everyday objects. In the course of recent centuries, and especially the last hundred years, the public first and artist later policy, failed to uphold art as an activity or a set of objects that enjoyed some distinction with respect to the other inhabitants of the universe. The unity of the artistic object with social action was broken. The remaining fragments, projected with the help of other emerging fragments around a non-existent centerpiece, determine the aesthetic expressions of our days. However, we not only lose the clarity of the limit of what art was, because there was also an overflow of art forms in other human products. The objects that accompany us in life acquire aspects that would only have been found in previous times in works of art. Consumers even come to prefer, among collective availability, products that emphasize on some aesthetic presentation rather than those that do not. How is it that it came to constitute itself in such a way? The process is, without a doubt, too complex. We can stop briefly to consider one of the clearest diagnoses of this situation: relating to categories of judgment about art. Kant proposed theoretical foundations for the aesthetic object, so that the judgement of art could be conducted using three positive categories, and their corresponding negative counterparts. Beauty has a preeminent position in this arrangement, consistent with the harmonic proportions of what is perceived as adequate to the human scale, producing pleasure without the mediation of any concept. If the adequacy overflows across a vast scale of perception, we have the sublime, and if the scale fails to be completed because of a tiny perceptual scope, we find the nice. The horrible, the ugly, and the ridiculous would be corresponding negative opposites of the three figures mentioned above. It follows that, from the application of these categories, human individuals act as a meter of the proportions for artistic categories. If, in the case of artwork, they feel that the fullness of their sensibility has been met, then the work is perceived as beautiful. If their sensibility cannot comprehend the entirety of dimensions involved, then individuals realize 
that the perceived object does not end in the process of sensitivity, and reflect something sublime (for example, before the vast and cloudless firmament of a starry night). If, however, individuals perceive an object without demanding the total reach of their sensibility, they are facing something that is just nice (a Kantian example is a wood carving miniature of a cathedral).

In the late eighteenth century, categories proposed by Kant were considered valid yet insufficient. The judgement of an individual is expected to be universal, in terms of how each one inside of oneself recognizes the human scale. In other words, knowing their own natural humanity to realize the necessary comparisons and to produces the judgement of that perceived. Clearly, when faced to the criticism that distinguishes modernity, the human individual shows a sensibility that extends according to the passage of times, due in part to the self-renewing character of the arts. In this aspect, the experience of art has been driven into the awareness of art: it deals with critical judgement and not only with immediate perception. Hegel analyses the process of judgment of art and his warnings are twofold. One of them is that beauty is applied as a category of judgment, in an ideal way. The other is that this ideal is modified historically. The idea, says Hegel in his Lectures on Aesthetics, is the unity of the concept and the objective, objectivity being the selfdevelopment of the concept. So, beauty cannot be understood as the only category to judge a work of art because the work itself is an objective realization of the concept, and in it has its own development. Hegel suggests that Kant had already separated the mere sensation of beauty from the notion of beauty but lacked "the concrete unity of concept and objectivity". This leads us to recognize that beauty is not only a content of consciousness-upon which to construct a judgement-but an objective presence, which is the work itself, where the reality of the unity of concept and objectivity is verified. Therefore, art is not only an experience, given that consciousness finds there the perception of the objective truth of a concept. In art, the concept coincides with objectivity, and that is its right.

The historical notion of beauty in its objective character is also a consciousness moving towards a greater freedom. Beauty consists of, according to this Hegelian vision, the creation of an ideal through the purification of what does not belong to art. We note that the journey of the freedom of spirit in its artistic objectification is seen by Hegel as the realization of the ideal of beauty, but he never supposed that, in his future-our present-, there could be an injunction on the ideal itself. For Hegel, the spiritual purification of art was meant to avoid that which "holds the remaining existence of the pollution of chance and externality". We have already asserted that art, especially in the last hundred years, has been "contaminated" by chance and externality. With this deviation, art no longer meets the dénouement envisaged by Hegel, consisting of a return "of the external existence to the spiritual", which is equivalent to concept and objectivity. As Hegel warns, romantic art involves the dissolution of the classical ideal. It is expected that the same romantic ideal be dissolved by the new era. What is important in this substitution of ideals is an observation that Hegel notes: that romantic art "makes this solution actually now appear clearly as dissolution". Art reaches full freedom when it is not submissive to the externality of "a valid objective content for itself and in itself" (as would be the classical ideal) and the "contribution to free oneself from the represented content". Presenting the dissolution itself becomes the new task of art in its history of objectification. The need to adapt at the same time to meaning and structure in a spiritual unity disappears. What remains is the full and complete freedom from historical necessity. Released from its content, modern art, encouraged by a critical manner, only counts on "the 
requirement to turn against the content so far is still valid". More than an affirmative unity, art becomes negative fragmentation: the mere opposition to the need for unity of meaning and form. From then on everything that complies with that opposition would be art.

Yet, beauty became that adaptation to unity. What has happened upon expanding the freedom of art from the unity, which guaranteed beauty? Beauty, Hegel said, is not only the concept but its union with objectivity. And what if this unity between concept and objectification is no longer necessary (and perhaps not even possible)? The consequence is the death of the ideal-of the ideal beauty. And the prosaic, the chance and the externality will take the place of the deceased ideal. In its fragmentation, art separates the path of its old unity in two: on the one hand art moves in the orbit of concepts as separate moments; on the other, in mere meaningless externalities. Adapted to the habit of criticism, artists begin to give preference to ideation and accompany-or even supplant - their works with particular conceptual explanations. The stage of the avant-garde is the punctual historical case, and aims to present a sum of impossibilities, whether dealing with the act of painting the movement, in futurism; essence, in abstractionism; the fourth dimension, in cubism; or the unconscious, in surrealism, among other intents. Conversely, they present the new subject of art by dispensing with the concept, or turning it into an abomination. We recall the declaration of the Dada Cannibalistic Manifesto, by Francis Picabia: "Dada is nothing, Dada means nothing". In the Avant-garde theatre they present shows referring to themselves as shows, as we can see in Pirandello's plays; poems that are only onomatopoeia, as in Marinetti's writings; paintings are only in one color, such as is seen White on White, by Malevich.

What follows, then, is a derivation of the unity of art, stipulated by Hegel, deviated separately towards its conceptual components or its material externality. Art ceases to appear as a spiritual unity in which the concept is no different from the objective development of its materialization. It is a condition in which the artistic process is fragmented but continues producing objects that may be called the meta-artistic condition. acts of conception, objectivity, and perception similar to those made for art, but the spiritual unity no longer exists, there is instead a rupture in every part of the process. The artist conceives the work, but no longer makes itv. The work, in turn, represents only its own presence. The public perceives, and turns to the ontological question or the intellectual criticism. Beauty, which was the categoric figure of judgment for art, is no longer useful to produce valid statements about the new type of works. Beauty has gone, together with the ideal established by the previous art, and we can say, with Hegel, that art has also disappeared. Artists no longer propose as an objective of their works making beauty perceivable. In turn, nor do the public of the meta-artistic expects to have an experience of beauty. The ideal has

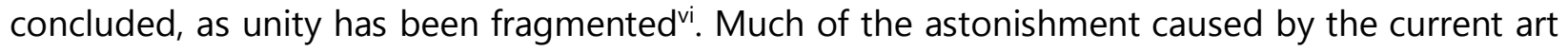
is due to the lack of the ideal of beauty when material objectification takes place in this process. Beauty is no longer a reference point for the art. Beauty has ceased to be an appropriate category to state the judgment about the perception of such objects labelled as meta-artistic. The theoretical assessment is that the process of the meta-artistic still has an effect which is analogous to the artistic effect (in fact, it is a further progression from the artistic, hence the prefix meta-). But in the value spectrum-detailed by Kant to describe the human scale and noted by Hegel as the conquest of historical freedom - their objective unity has changed. The human scale is still present and continues to be the purpose of meta-artistic expression. But the current scale of the human includes the blurring of the boundaries of art, and the spread into the field of art of non- 
formerly-art social products. Therefore, what we would continue to distinguish as meta-artistic objects, as opposed to objects in the rest of the social world, would be the intensity of its sensitive insistence. Meta-artistic object is like a work of art, a unique object of perception: one thing to be perceived beyond all other possible considerations or additions that could divert to other purposes within the human community.

Given this situation, I propose a category applicable for the judgment of contemporary art or the process of the meta-artistic: aesthetic impact. What was Duchamp trying to achieve with passing off a urinal as a sculpture? Certainly not the beauty of the object, but the transformation of a useful industrial object into a thing to be perceived (and not to be used). The resulting effect is an aesthetic impact, or a punch or shock on the senses. Chilean poet Vicente Huidobro expresses this well in his Ars Poetica. "That the listener's soul be left trembling". The shiver of sensitivity is caused by perceiving the aesthetic impact: things have been presented so that they capture extreme scenarios, with or without the intervention of beauty, but almost always conducting the displacement of past experiences of the public towards unprecedented limits. In this way, the meta-artistic continues the function of art. What changes is that this feature is no longer achieved with the ideal unity. Without being art properly, or without being totally confused with other things in the world, the meta-artistic object aims to leave us with an aesthetic impact, a new imprint on our ability to feel. The judgement of the meta-artistic can be analogous to that of art; but it is necessary to adopt a different category besides beauty. Perhaps it could be found in the measurement of aesthetic impact instead. By observing contemporary expression, we can explain and appreciate a huge sector of objects in which the primary category applied aesthetically is what the creator proposes, without committing the injustice of requiring the present world to continue to validate the category of beauty for art, which no longer belongs to it as a central value.

\section{Notes}

' I proposed this concept in 2003 and it is treated in my book (2007) Los objetos meta-artísticos y otros ensayos sobre la sensibilidad contemporánea [Meta-artistic Objects and Other Essays on Contemporary Sensibility], Mexico: Azafrán y Cinabrio.

ii In this connection, see my book (2013) Ontología y Vanguardias. Orígenes de la estetica de la fragmentacion [Ontology and Avant-Gard. Origins of the Aesthetics of Fragmentation], Mexico: Calygramma-INBA-CONACULTA.

iii See in the mentioned book, in footnote 1, the essay El impacto estetico como categoría meta-artística ["The aesthetic impact as a meta-artistic category"].

iv For a particular presentation of significant orbs of high art, popular art and folk art, see my essay (2003) Algunos criterios teóricos para la formulación de políticas culturales [Some theoretical approaches in the formulation of cultural policies], Colmena Universitaria, 81, 57-77. 
9 | The Nature and Concept of Meta-artistic Objects

\footnotetext{
' We must insist on the foundational role of Duchamp's proposal to exhibit a urinal as a sculpture, a feat which was repeated by Warhol's soap box. That "sculpture" definitely establishes the historic presence of meta-artistic development.

vi In this respect see the book I edited (2005, 2nd revised and greatly enlarged: 2007) La Muerte de Venus: la fragmentación en la estética actual[ The Death of Venus: The Fragmentation in the Aesthetic of Our Time]. Mexico: Azafrán y Cinabrio.
} 